\title{
Caso del Buque Norcoreano Mu Du Bong
}

Con información oficial de la Secretaría de Relaciones Exteriores (SRE), el pasado 14 de junio de 2014:

El buque norcoreano llamado "Mu Du Bong” encalló en un área protegida en el puerto de Veracruz, el buque provocó daños a la zona denominada "Arrecifal Lobos-Tuxpan” la autoridades mexicanas determinaron que el buque debía reparar el daño y pagar una serie de multas, las cuales fueron pagadas el 3 de diciembre de ese mismo año. Antes de que el buque zarpara a su destino le fue notificado al gobierno mexicano, que dicho buque pertenecía a una de las empresas que se encuentre en la lista formulada por el Consejo de Seguridad que tiene indicios de suministrar armamento a la República Popular Democrática de Corea a la cual se le han formulado una serie de sanciones y resoluciones para evitar que dicho país siga rearmándose y poner en peligro el equilibrio en la región asiática. ${ }^{1}$

Por su parte, la SRE publicó en el Diario Oficial de la Federación, el 13 de abril de 2015, el "Acuerdo por el que se da a conocer el texto de diversas resoluciones emitidas por el Consejo de Seguridad de la Organización de las Naciones Unidas". Las razones que se exponen en el apartado "Considerando" del Acuerdo, para tomar en cuenta las resoluciones del Consejo de Seguridad son las siguientes:

1 Secretaría de Relaciones Exteriores, "En el caso del buque Mu Du Bong, México cumple con sus obligaciones como Estado miembro de la ONU”, Comunicado 185 Jueves 9 de abril de 2015, http://saladeprensa.sre.gob.mx/index.php/es/comunicados/5901-185 [fecha de consulta 24 de agosto 2015] 
Esta revista forma parte del acervo de la Biblioteca Jurídica Virtual del Instituto de Investigaciones Jurídicas de la UNAM www.juridicas.unam. $\mathrm{mx}$

Juan Manuel Gómez-Robledo Verduzco, Subsecretario para Asuntos Multilaterales y Derechos Humanos de la Secretaría de Relaciones Exteriores, con fundamento en lo dispuesto por los artículos 133 de la Constitución Política de los Estados Unidos Mexicanos, 28, fracción I de la Ley Orgánica de la Administración Pública Federal, 5 inciso D), y 8, fracciones VIII y XVI del Reglamento Interior de la Secretaría de Relaciones Exteriores, y

\section{CONSIDERANDO}

Que el 26 de junio de 1945 México suscribió la Carta de la Organización de las Naciones Unidas (Carta de la ONU), Tratado que fue aprobado por el Senado de la República el 5 de octubre de 1945, publicado en el Diario Oficial de la Federación el 17 de octubre y ratificado el 7 de noviembre de ese mismo año;

Que con arreglo al artículo 24 de la Carta de la ONU, a fin de asegurar la acción rápida y eficaz por parte de dicha Organización, los Miembros de las Naciones Unidas confirieron al Consejo de Seguridad la responsabilidad primordial de mantener la paz y la seguridad internacionales y reconocen que dicho Consejo actúa en nombre de ellos al desempeñar las funciones que le impone aquella responsabilidad;

Que conforme al Capítulo VII de la Carta de la ONU, el Consejo de Seguridad puede decidir qué medidas coercitivas habrán de emplearse para hacer efectivas sus decisiones con objeto de mantener o restablecer la paz y la seguridad internacionales y ordenar a los Estados Miembros de las Naciones Unidas aplicar las mismas, entre las que se encuentran la interrupción total o parcial de las relaciones económicas, comúnmente denominadas «embargos» o «sanciones económicas»; Que con arreglo al artículo 25 de la Carta de la ONU, los Estados Miembros convinieron en aceptar y cumplir las decisiones del Consejo de Seguridad y que, consecuentemente, su inobservancia constituye la violación de una obligación internacional que genera responsabilidades.

En dicho Acuerdo se mencionan las prohibiciones que tiene la República Democrática de Corea (RDC) respecto al uso de armas nucleares, misiles balísticos u otras armas de destrucción masiva que contribuyan al desequilibrio en la región asiática y que amenacen la paz internacional. El Acuerdo está conformado por las Resoluciones aprobadas por el Consejo de Seguridad de las Naciones Unidas: 1) Resolución 1718 (2006); 2) Resolución 1874(2009); 3) Resolución 2087 (2013) y; 4) Resolución 2094 (2013). A grandes rasgos, se puede señalar que en las resoluciones se habla de que se condena el ensayo nuclear anunciado el 9 de octubre de 2006, anun- 
ciado por Corea del Norte; además señalan las exigencias del Consejo de Seguridad de las Naciones Unidas respecto a: 1) que la República Popular Democrática de Corea no haga nuevos ensayos nucleares ni lanzamientos de misiles balísticos; 2) que se retracte de retirarse del Tratado sobre la no proliferación de armas nucleares que en consecuencia traería la desestabilidad en la región asiática y amenazaría la paz internacional, como consecuencia de las dos acciones anteriores el Consejo prohíbe cualquier ayuda de alguno de los países miembros de la Organización para ayudar a Corea del Norte en el uso de armas de cualquier índole, restricción de flujos financieros de alguno de los países miembros con excepción que sean por razones humanitarias.

Lo que debemos destacar de este acuerdo aplicable al caso del buque norcoreano Mu Du Bong son los siguientes párrafos:

Resolución 1718(2006)

Párrafo 8

a) Todos los Estados Miembros impidan el suministro, la venta o transferencia directos o indirectos a la República Popular Democrática de Corea, a través de su territorio o por sus nacionales, o con naves o aeronaves de su pabellón, tengan o no origen en su territorio, de:

i) Todos los carros de combate, vehículos blindados de combate, sistemas de artillería de gran calibre, aeronaves de combate, helicópteros de ataque, naves de guerra, misiles o sistemas de misiles, como se definen a los efectos del Registro de Armas Convencionales de las Naciones Unidas, o material conexo, incluidas piezas de repuesto, o los artículos determinados por el Consejo de Seguridad o el Comité establecido en virtud del párrafo 12 infra(el Comité);

ii) Todos los artículos, materiales, equipos, bienes y tecnología indicados en las listas de los documentos S/2006/814 y S/2006/815, salvo que en un plazo de 14 días a partir de la aprobación de la presente resolución el Comité haya modificado o complementado sus disposiciones teniendo asimismo en cuenta la lista del documento $\mathrm{S} / 2006 / 816$, así como todos los demás artículos, materiales, equipos, bienes y tecnología, determinados por el Consejo de Seguridad o el Comité, que pudieran contribuir a los programas 
Esta revista forma parte del acervo de la Biblioteca Jurídica Virtual del Instituto de Investigaciones Jurídicas de la UNAM

de la República Popular Democrática de Corea relacionados con actividades nucleares, misiles balísticos u otras armas de destrucción en masa;

iii) Todo artículo de lujo;

b) Todos los Estados Miembros impidan toda transferencia a la República Popular Democrática de Corea por sus nacionales o desde sus territorios, o desde la República Popular Democrática de Corea por sus naciones o desde su territorio, de capacitación técnica, asesoramiento, servicios o asistencia relacionados con el suministro, la fabricación, la conservación o el uso de los artículos comprendidos en los inciso i) y ii) del apartado a) supra.

c) Todos los Estados miembros adopten las medidas necesarias para impedir el ingreso en su territorio o el tránsito por él a las personas designadas por el Comité o por el Consejo de Seguridad por ser responsables de las políticas de la República Popular Democrática de Corea, incluso de apoyarlas o promoverlas, referentes a los programas relacionados con actividades nucleares, misiles balísticos y otras armas de destrucción en masa de la República Popular Democrática de Corea, junto con sus familiares, en el entendimiento de que nada de lo dispuesto en el presente párrafo obligará a un Estado a negar a sus propios nacionales el ingreso en su territorio.

Resolución 1874 (2009)

El párrafo 10 se refiere que los Estados miembros notifiquen al comité cualquier observación respecto a venta, el suministro o la transferencia de armas pequeñas o ligeras a la República Popular Democrática de Corea, el párrafo 11 exhorta a todos los Estados miembros a que inspeccionen de conformidad con su legislación interna y las facultades que ésta les confiere y en consonancia con el derecho internacional, toda la carga que esté destinada a la República Popular Democrática de Corea o proceda de ese país, en su territorio, incluidos los puertos marítimos, si el Estado de que se trate tiene información que ofrezca motivos razonables para creer que la carga contiene artículos prohibidos en los que hace mención el párrafo 8. Los siguientes párrafos 12 y 13 se refieren a que los Estados miembros pueden realizar una inspección de las naves en alta mar o se pueda llevar la nave a un puerto cercano para dicha acción, siempre y cuando cuente con la información su- 
ficiente. En los párrafos 14, 15 y 16 hablan sobre si se realiza tal inspección, los Estados miembros deben presentar un informe detallado al Comité.

Resolución 20877(2013)

Específica las personas y empresas quienes tienen sus activos congelados y no tienen permiso de viajar, esto debido a que contribuyeron al abastecimiento de armamento a la República Popular Democrática de Corea.

Resolución 2094 (2013)

En el párrafo 16 habla de nuevo sobre la inspección de toda carga de algún buque que se encuentre en su territorio o en tránsito por él y cuyo origen o destino sea la RPDC, si recaba información fidedigna sobre la prohibición de artículos del párrafo 8, el Estado miembro debe asegurarse de la aplicación estricta de esta y las anteriores resoluciones. El párrafo 17 se refiere a que si cualquier buque se niega a permitir una inspección después de que esta haya sido autorizada por el Estado del pabellón, o si cualquier buque con pabellón de la RPDC se niega a ser inspeccionado, los Estados miembros denegarán a dicho buque la entrada en sus puertos y por último cabe destacar el párrafo 19 donde se les solicita a los Estados Miembros que comuniquen al Comité cualquier información disponible sobre las transferencias a otras empresas de aeronaves o buques de la RPDC que puedan haberse efectuado para evadir las sanciones impuestas por las resoluciones anteriores o por la presente resolución debe dar aviso al Comité y proporcionar la información para que pueda difundirse. ${ }^{2}$

Al momento de detener el buque, el Consejo de Seguridad determinó que para revisar el caso, un grupo de expertos fueran a inspeccionarlo, dicho visita se llevó a cabo entre el 17 y 19 de septiembre de 2014. El análisis del caso aún no concluye, por lo que aún nuestro gobierno no ha podido dejar que el buque zarpe, lo que en los medios de comunicación y el representante de la República Popular Democrática de Corea ante la ONU

2 El Acuerdo y los detalles de cada párrafo de las resoluciones fueron extraídas del Diario Oficial de la Federación, puede consultarse en línea con la siguiente dirección http: / / dof.gob. $m_{x} /$ nota_detalle.php?codigo $=5388576 \&$ fecha $=13 / 04 / 2015$. [fecha de consulta 25 de agosto de 2015]. 
Esta revista forma parte del acervo de la Biblioteca Jurídica Virtual del Instituto de Investigaciones Jurídicas de la UNAM www.juridicas.unam. $\mathrm{mx}$

An Myong Hun ha determinado que su gobierno utilizará cualquier medio para que inmediatamente sea liberado su buque y pueda llegar a su territorio, además han comunicado que la relación entre su país y el nuestro se encuentra en una serie de ficciones por dicho acontecimiento. ${ }^{3}$

Cabe destacar que en el buque tenía una tripulación de 33 norcoreanos, a los cuales, desde que encalló el buque, el gobierno mexicano ha velado por las necesidades básicas de estos tripulantes. Según información de los medios y de la Secretaría de Relaciones Exteriores, a la tripulación se les ha otorgado una visa especial donde estos gozaban de libre tránsito, la visa expiró el pasado 15 de abril de 2015, por lo que, parte de la tripulación se acercó el 14 de abril al Instituto Nacional de Migración para que se les otorgara una visa humanitaria dado que su estancia legal expiraba el día siguiente. La Secretaría de Relaciones Exteriores vio como alternativa la repatriación de los tripulantes pero de acuerdo con las ordenes de su gobierno no piensan irse si no es con el buque. ${ }^{4}$

Elaborado por Ingrid Rodríguez Gómez

3 El Economista, "Buque origina roce entre Norcorea y México", en línea http:// eleconomista.com. $\mathrm{mx}$ /sociedad / 2015/04/08/corea-norte-mexico-protagonizaron-roce-diplomaticobuque. [fecha de consulta 25 de agosto de 2015]

4 Villa, Itzel Corresponsal, "Tripulación del buque norcoreano solicita a México visa humanitaria", publicado el 14 de abril de 2015, en línea: http: / / www.elfinanciero.com.mx/mundo/ tripulacion-del-buque-norcoreano-solicita-a-mexico-visa-humanitaria.html[ fecha de consulta 25 de agosto de 2015] 